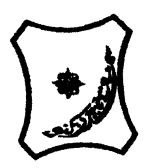

Bayero Journal of Pure and Applied Sciences, 12(1): 280 - 284

ISSN $2006-6996$

\title{
COMPARATIVE STUDY ON THE CORROSION BEHAVIOR OF MILD STEEL IN EFFLUENTS, SEA AND FRESH WATER
}

Naja'atu Auwal Usman, Usman Muhammad Tukur and Bishir Usman*

Department of Pure and Industrial Chemistry, Faculty of Physical Sciences, College of Natural and

Pharmaceutical Sciences Bayero University, P. M. B. 3011, Kano State. Nigeria

*Corresponding author: busman.chm@buk.edu.ng

\section{ABSTRACT}

The corrosion rate of mild steel behavior exposed to effluents (EF), sea water (SW) and fresh water (FW) were study using weight loss, scanning electron spectroscopy (SEM) and $x$-rays diffraction (XRD). The results show that the weight loss of mild steel in different water samples increases with increasing in immersion time and temperature respectively. The corrosion rate of water was found to be higher in sea water $(0.003 \mathrm{~g} \mathrm{~cm}$ week $\left.^{-2}\right)$, effluents $\left(0.021 \mathrm{~g} \mathrm{~cm}^{-2}\right.$ week $\left.{ }^{-2}\right)$ and fresh water $\left(0.020 \mathrm{~g} \mathrm{~cm}^{-2}\right.$ week $\left.\mathrm{k}^{-2}\right)$ respectively. The corrosion rate and behaviour of mild steel in the water sample were affected by some physical and chemical parameters such as $\mathrm{pH}$, turbidity, conductivity and biological oxygen demand (BOD). Effluents (EF) were found to have pH (5.20), turbidity (13.3nut), conductivity $(4203 \mu \mathrm{s} / \mathrm{cm})$ and BOD $\left(0.119 \mathrm{mg} / \mathrm{dm}^{3}\right)$. Sea water (SW) were found to have $\mathrm{pH}(7.60)$, turbidity $(173 \mathrm{nut})$, conductivity $(30800 \mu \mathrm{s} / \mathrm{cm})$ and BOD $\left(0.028 \mathrm{mg} / \mathrm{dm}^{3}\right)$. Fresh water (FW) were found to have pH (7.60), turbidity (127nut), conductivity $(419 \mu \mathrm{s} / \mathrm{cm})$ and BOD $\left(0.651 \mathrm{mg} / \mathrm{dm}^{3}\right)$. Similarly, the presences of elements such as chloride ion ( $\mathrm{Cr}$ ), $\mathrm{Fe}, \mathrm{Ba}, \mathrm{Br}, \mathrm{S}, \mathrm{La}, \mathrm{Nb}$ and Mo from XRF confirm that the corrosion rate is higher in sea water. SEM microgram revealed that corrosion rates of EF, SW and FW were of different nature, both the samples have rough surface with various cracks after immersion. This clearly shows that the sea water has the highest corrosion products follow by effluent than fresh water sample. Both the weight loss and corrosion rate increases as the immersion time and temperature increases.

Keywords: Corrosion rate, Mild steel, Weight loss, AAS, SEM, XRF, Immersion Time, Temperature

\section{INTRODUCTION}

Corrosion of mild steel is an electro-chemical reaction between the metal and its environment in which the metal reverts to iron oxide (Alo and Ibitoye, 2015). The electro-chemical process causes a gradual alteration or wearing away of the metal surface and since the process returns the metal to its stable thermodynamic state, the action is considered as a degradation of the material. For corrosion to take place there must be presence of an electrolyte like water, salt water, soil or corrosive medium. However, the appearance of rusted metal work is not very much acceptable in usual industrial practice (Mobin and Shabnam, 2010). Metals has numerous application in industrial and technological sector of development, an in depth study of corrosion, its form, prevention and control measures are necessary. Corrosion is a natural process that reduces the binding energy in metals with the end result involving a metal being oxidized as the bulk metal loose one or more electrons. The lost electrons are conducted through the bulk metal to another site where they are reduced (Arya and Zaidi, 2014).

Water is one of the most important compounds to the ecosystem. Better quality of water is described by its physical, chemical and biological characteristics. Due to the increased human population, industrialization, use of fertilizers in agriculture and man-made activity the water gets polluted. The natural aquatic resources are causing heavy and varied pollution in aquatic environment leading to water quality and depletion of aquatic biota (Al-Moubaraki and AlRushud, 2018). The physico-chemical parameters of water and the dependence of all life process of these factors make it desirable to take as an environmentally viable or not (Zou, 2011). The leachate produced by waste disposal sites contains a large amount of contaminants which are likely to pollute ground water (Raman and Sathiyanarayanan, 2011). 
Special Conference Edition, November, 2019

Mild steel is used in different Engineering applications for the production of some automobile components, structural shapes and sheets that are used in pipelines, buildings, plants, bridges and tin cans (Orozco, 2017). Mild steel is known for its high carbon content of about $(0.2 \%$ to $2.1 \%)$, manganese $(1.65 \%)$, copper $(0.6 \%)$, silicon $(0.6 \%)(\mathrm{Wu}, 2017)$. It is produced from steel which is extracted from pig iron it is also less expensive to produce and is readily available. It has outstanding ductility and toughness, high machinability and weld ability which make its applications possible in the engineering fields (Samina, 2011). The application for which mild steel was developed generally did not involve corrosion resistance as a primary consideration; corrosion resistance of metals and alloys is a basic property related to the ease with which these metals react with a given environment, utilization of metallic containers, tanks and pots for storage of water, unknowingly, corrosion process of metal are gradually being taking place in different media, yet there is little corrosion studies in this, therefore, there is need for intense study (Gasim, 2015). The aim of this study is to find out the corrosion behaviour of mild steel in water environments.

\section{MATERIALS AND METHODS}

\section{Reagents}

All the reagents used for this research are of analytical grade including acetone, and ethanol.

\section{Metal Coupon Preparation}

The metal coupons were obtained from Mechanical Engineering Department of Bayero University Kano (BUK). The metal coupons were cut into dimension of $2 \mathrm{~cm} \times 2 \mathrm{~cm} \times 0.2 \mathrm{~cm}$. They were polished with different grades of emery paper $(400,800,1200)$, washed with distilled water, degrease with ethanol and acetone, dried in air and stored in desiccator prior to experimental. The initial weight of each sample was taken and recorded.

\section{Samples Collection}

Three different samples of water (Effluent, Seawater, and Freshwater) were collected from different environments, Sharada industrial area of Kano state, Bar beach of Lagos state and Gwammaja Housing Estate Kano state respectively. Water samples collected in polyethene bottles according to APHA9060A (2005).

\section{Scanning Electron Microscopy (SEM)}

Surface morphologies of mild steel coupons after immersion was studied using (PRO: $X$ : Phenonm World 800-07334) model, manufactured by phenom World Eindhoven, Netherlands. Scanned images of mild steel coupon immersed in Sea water, Fresh water and Effluent for one week were taken at an accelerating voltage $15.00 \mathrm{kV}$ and $x 500$ magnification.

\section{Weight Loss}

To study the effect of immersion time, the prepared weighed mild steel coupon was immersed completely in $100 \mathrm{~cm}^{3}$ beaker containing $50 \mathrm{~cm}^{3}$ of each sample solution. The coupon was removed from water sample at time interval of 1,2,3,4 and 5 weeks respectively. The different in weight of mild steel coupon before and after immersion was recorded as weight loss (Manjare et al., 2010). The immersion time with relatively higher weight loss was adopted as optimum immersion time (Durowaye et al., 2014).

\section{Determination of Corrosion Rate}

The corrosion rate were calculated from weight loss before and after exposure and divide by the total exposed area and the total exposure time so that appropriate conversion constants are used to get the rate in the required units (Wasim, 2018).

Effect of Temperature To investigate the effect of temperature, the prepared weighted mild steel coupon was immersed in each water sample for 1 hour immersion time at temperature range of $298,303,308,313,318$ and $322 \mathrm{~K}$. The corrosion rate and weight loss was calculated.

\section{RESULTS AND DISCUSSION}

The result obtained from Table 1 shows that the weight loss of mild steel in sea water, fresh water and effluent increases with increase in immersion time. The immersion time of week one investigated, the weight loss of mild steel in sea water, fresh water and effluent were 0.125 , 0.009 and $0.006 \mathrm{~g}$ while at highest immersion time of weeks five the weight loss increases from $0.036,0.040$ and $0.040 \mathrm{~g}$ respectively. This indicate that the more the mild steel is exposed to the corrosive environment the higher the contact between them, hence the higher the rate of corrosion will increase (Fang et al., 2010). 
Special Conference Edition, November, 2019

Table 1: Weight Loss of Mild Steel at Different Immersion Time

\begin{tabular}{clll} 
Time (Weeks) & Sea Water & $\begin{array}{c}\text { Weight Loss }(\mathbf{g}) \\
\text { Fresh Water }\end{array}$ & Effluent \\
\hline 1 & 0.125 & 0.009 & 0.006 \\
2 & 0.009 & 0.019 & 0.012 \\
3 & 0.017 & 0.016 & 0.016 \\
4 & 0.042 & 0.050 & 0.015 \\
5 & 0.036 & 0.040 & 0.040 \\
\hline
\end{tabular}

Table 2 shows the variation of corrosion rate at different time. It showed that the corrosion rate decreases with increase in time. At least corrosion rate of 1 week, the corrosion rate of mild steel was $0.031,0.002$ and $0.002 \mathrm{~g} / \mathrm{cm}^{2}$ week. At highest corrosion rate of 5 weeks, the corrosion rate of mild steel was the same $0.002,0.002$ and $0.002 \mathrm{~g} / \mathrm{cm}^{2}$ week. It can be observed that after some weeks the corrosion rate drastically increased. This is due to corroding surface which doesn't allow the interact with the corroding environment. It can be seeing in table 3, at 298 and 303K, both the corrosion decreases while increases in other temperatures.

\section{Effect of Temperature}

Table 3, shows the variation of corrosion rate for the corrosion of mild steel of sample solutions at different temperature. The result showed that the corrosion rate increases with increase in temperature due to increase in corrosion film, it has been established that corrosion film plays a major role in decrease of corrosion rates. At least temperature used (298K) the corrosion rate of mild steel in sea water, fresh water and effluent were $(0.00003,0.0004$ and $0.0036 \mathrm{~g} / \mathrm{cm}^{2} \mathrm{hr}$ ) with increasing the temperature to $(322 \mathrm{~K})$ the corrosion rate of mild steel in sea water, fresh water and effluent increases to $\left(0.00033,0.00023\right.$ and $\left.0.00025 \mathrm{~g} / \mathrm{cm}^{2} \mathrm{hr}\right)$.

Table 2: Weight Loss and Corrosion Rate of Mild Steel at Different Immersion Time

\begin{tabular}{cllllll}
\hline Time (Week) & \multicolumn{2}{c}{ Weight Loss $(\mathbf{g})$} & \multicolumn{2}{c}{ Corrosion Rate $\mathbf{( g ~ c m}^{-2}$ week $\left.^{-2}\right)$} \\
& $\begin{array}{c}\text { Sea } \\
\text { Water }\end{array}$ & $\begin{array}{l}\text { Fresh } \\
\text { Water }\end{array}$ & Effluent & $\begin{array}{c}\text { Sea } \\
\text { Water }\end{array}$ & $\begin{array}{l}\text { Fresh } \\
\text { Water }\end{array}$ & \\
\hline 1 & 0.125 & 0.009 & 0.006 & 0.031 & 0.002 & 0.002 \\
2 & 0.009 & 0.019 & 0.012 & 0.001 & 0.002 & 0.002 \\
3 & 0.017 & 0.016 & 0.016 & 0.001 & 0.001 & 0.001 \\
4 & 0.042 & 0.050 & 0.015 & 0.003 & 0.003 & 0.001 \\
5 & 0.036 & 0.040 & 0.040 & 0.002 & 0.002 & 0.002 \\
\hline
\end{tabular}

Table 3: Weight Loss and Corrosion Rate of Mild Steel at Different Temperature

\begin{tabular}{cllllll}
\hline Temperature (K) & \multicolumn{3}{c}{ Weight Loss (g) } & \multicolumn{2}{c}{ Corrosion Rate $\mathbf{( g ~ c m}^{-\mathbf{2}} \mathbf{h r}^{-\mathbf{1}} \mathbf{)}$} \\
& $\begin{array}{c}\text { Sea } \\
\text { Water }\end{array}$ & $\begin{array}{l}\text { Fresh } \\
\text { Water }\end{array}$ & Effluent & $\begin{array}{l}\text { Sea } \\
\text { Water }\end{array}$ & $\begin{array}{l}\text { Fresh } \\
\text { Water }\end{array}$ & \\
\hline 298 & 0.0001 & 0.0016 & 0.0009 & 0.00003 & 0.00040 & 0.00360 \\
303 & 0.0005 & 0.0010 & 0.0015 & 0.00013 & 0.00025 & 0.00038 \\
308 & 0.0004 & 0.0031 & 0.0010 & 0.00010 & 0.00078 & 0.00025 \\
313 & 0.0002 & 0.0002 & 0.0001 & 0.00005 & 0.00005 & 0.00003 \\
318 & 0.0014 & 0.0044 & 0.0028 & 0.00035 & 0.00110 & 0.00070 \\
322 & 0.0013 & 0.0009 & 0.0010 & 0.00033 & 0.00023 & 0.00025 \\
\hline
\end{tabular}

Figure 1, shows the SEM micrographs of different coupons of mild steel in sea water, fresh water and effluent after immersion. Both the sample has rough surface with various cracks after immersion for two weeks. This clearly shows that the effluent has the highest corrosion products follows by fresh water than sea water sample (Rajesh et al., 2014). Effluent serve as a good medium for corrosion due to the presence of other organic compounds in the sample which alter the metal coupon than follows by fresh water than sea water. 


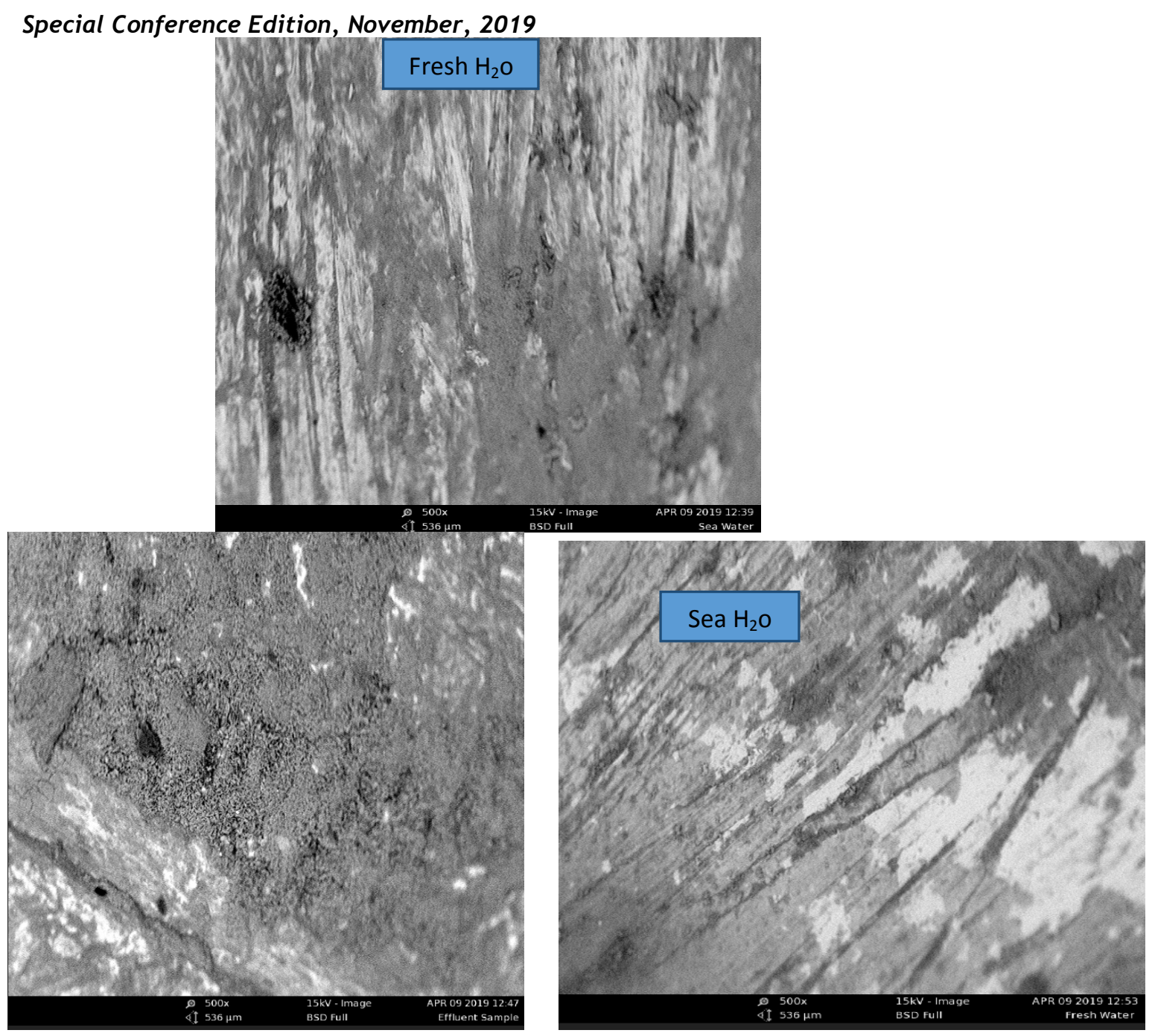

Figure 1: SEM Micrograph of mild steels immersed in different water environments.

\section{CONCLUSION}

Based on the results obtained, the corrosion rate of different water samples, increases with increase in immersion time in all the water

\section{REFERENCES}

Mobin, M. And Shabnam, H., (2010). Corrosion Behavior of Mild Steel and Ss 3041 in Presence of Dissolved Copper Journal of Minerals \& Materials Characterization \& Engineering, Vol. 9, No.12, and Pp. 1113-1130.

Al-Moubaraki, A. H. And Al-Rushud Hindawi, H. $\mathrm{H}$. (2018). International Journal of Corrosion, Article Id 2381287, 15 pp

Arif Ma, Agung B, Suharyo Os, Pratisna $P$ (2018). The Effect of Protective Coatings Using L-5a Type Toward Corrosion Rate On Mild Steel Grade a Material (Case Study in Indonesia Warship). J Material Sci Eng 7: 470. Doi: 10.4172/21690022.1000470 . samples while both the weight loss and corrosion rate are increases as the temperature increased, high temperature produce more severe corrosion condition

Lawson E.O. (2011), Physico-Chemical Parameters and Heavy Metal Contents of Water from The Mangrove Swamps of Lagos Lagoon, Lagos, Nigeria Advances in Biological Research 5 (1): 08- 21

Zou Y., Wanga A. J. B, Zheng Y.Y. (2011) Electrochemical Techniques for Determining Corrosion Rate of Rusted Steel in Seawater, Corrosion Science 53 208-216

Arya S. And Zaidi J., (2014) Groundwater Quality Assessment of Kanpur City Using Water Quality Index American Journal of Sustainable Cities and Society Issue 3, Vol. 1 Issn 2319 - 7277 
Special Conference Edition, November, 2019

Raman N. And Sathiyanarayanan D., (2011) Quality Assessment of Ground Water in Pallavapuram Municipal Solid Waste Dumpsite Area Nearer to Pallavaram in Chennai, Tamilnadu Vol.4, No.2, 481487 Issn: 0974-1496 Coden: Rjcabp

Fang H., Brown B., Nešić S., (2010) High Salt Concentration Effects on Co2 Corrosion and $\mathrm{H}_{2} \mathrm{~S}$ Corrosion 10, Paper no.10276, NACE International, Houston, Texas.

Samina M., Karim A. And Venkatachalam A. (2011) Corrosion Study of Iron and Copper Metals and Brass Alloy in Different Medium E-Journal of Chemistry 8(S1), S344-S348.

Wu J., Pang K., Peng D., Wu J., Bao Y., Li X., (2017) Corrosion Behaviors of Carbon Steels in Artificially Simulated and Accelerated Marine Environment International Journal of Electrochemical Science 12 pp 1216 - 1231, Doi: 10.20864.

Orozco-Cruz R., Ávila E., Mejía E., Pérez T., Contreras A., Galván-Martínez R., (2017) In Situ Corrosion Study of Copper and Copper-Alloys Exposed to Natural Seawater of the Veracruz Port (Gulf of Mexico) International Journal of Electrochemical Science 12, 3133 3152, Doi: 10.20964.

Rajesh V., Monica C. L., Kalyani D. S., Rao S. S (2014) Analysis of Corrosion Rates of Mild Steel, Copper and Aluminium in Underground Water Samples of Krishna District, Andhra Pradesh, India International Journal of Advance Research in Science and Engineering Ijarse, Vol. No.3, Issue No.12.

Durowaye S.I., Alabi A.G.F, Sekunowo O.I., Bolasodun B., Rufai I.O. (2014) Effects of $\mathrm{Ph}$ Variation On Corrosion of Mild Steel in Bore-Hole Water Using $1 \mathrm{~m}$ Sodium Hydroxide Solution International Journal of Engineering and Technology Volume 4 No. 3.

Oguike R. S. (2014) Corrosion Studies on Stainless Steel (Fe6956) In Hydrochloric Acid Solution Advances in Materials Physics and Chemistry, 4, 153-163.

Alo Oluwaseun A. And Ibitoye Simeon A. (2015) Effect of Induced Stress on the Corrosion Rate of Medium Carbon Steel in Saline Environment Journal of Chemical Engineering and Materials Science Vol. 6(4), Pp. 52-59.
Manjare S. A., Vhanalakar S. A. and Muley D. V. (2010) Analysis of Water Quality Using Physico-Chemical Parameters Tamdalge Tank in Kolhapur District, Maharashtra. International Journal of Advanced Biotechnology and Research Issn 09762612, Vol 1, Issue 2, Pp 115-119.

Gasim A. B. (2014) Measurement Some of Physio-Chemical Parameters in Tigris River near The Center of Baghdad City J. Thi-Qar Sci. Vol.5 (1).

Wasim M. (2018), External Corrosion and Its Effects on Mechanical Properties of Buried Metal Pipes a Thesis Submitted in Fulfilment of the Requirements for the Degree of Doctor of Philosophy Unpublished. 